University of Wollongong

Research Online

Australian Institute for Innovative Materials -

Papers

Australian Institute for Innovative Materials

$1-1-2018$

Effect of electrochemical oxidation and reduction on cell de-adhesion at the conducting polymer-live cell interface as revealed by single cell force spectroscopy

Hongrui Zhang

University of Wollongong, hz215@uowmail.edu.au

Qi Gu

Chinese Academy of Sciences, University of Wollongong, qg863@uowmail.edu.au

Gordon G. Wallace

University of Wollongong, gwallace@uow.edu.au

Michael J. Higgins

University of Wollongong, mhiggins@uow.edu.au

Follow this and additional works at: https://ro.uow.edu.au/aiimpapers

Part of the Engineering Commons, and the Physical Sciences and Mathematics Commons

Research Online is the open access institutional repository for the University of Wollongong. For further information contact the UOW Library: research-pubs@uow.edu.au 


\title{
Effect of electrochemical oxidation and reduction on cell de-adhesion at the conducting polymer-live cell interface as revealed by single cell force spectroscopy
}

\author{
Abstract \\ Cell adhesion on conducting polymers is important in organic bioelectronics, including applications such \\ as electronically switchable surfaces and electrochemical transistors. There is a fundamental interest in \\ understanding the conducting polymer-cellular interface though as yet no direct measurements to \\ quantify the cell adhesion forces and energies, particularly at the molecular level, have been undertaken. \\ Here, the authors apply electrochemical-single cell force spectroscopy (EC-SCFS) to directly quantify the \\ de-adhesion forces between single L929 fibroblast cells and polypyrrole doped with dodecylbenzene \\ sulfonate (PPy-DBSA) under electrical stimulation. The EC-SCFS reveals single cell de-adhesion forces of \\ $0.65 \mathrm{nN}$ on PPy-DBSA films with adsorbed fibronectin (FN) protein. Blocking experiments by introducing \\ antibodies show that cell de-adhesion is largely due to the binding ( $\sim 60 \%$ of interactions) of cell-surface \\ $\alpha 5 \beta 1$ integrin receptors. Electrochemical oxidation and reduction of PPy-DBSA during initial adsorption of \\ fibronectin cause a significant decrease in the single cell de-adhesion forces to $\sim 0.4 \mathrm{nN}$, which is \\ suggested to relate to electrical stimulation effects on reducing $\mathrm{FN}$ adsorption on the polymer. In \\ contrast, when electrical stimulation is applied after protein adsorption is established and during the EC- \\ SCFS measurements, the single cell de-adhesion is significantly enhanced on the oxidized polymer \\ compared to the reduced and nonbiased polymer. The study highlights the use of EC-SCFS to directly \\ quantify cell adhesion on electrode surfaces, as well as the ability to probe molecular-level interactions \\ such as integrin receptor-FN complexes with forces of $\sim 50-100 \mathrm{pN}$. \\ Disciplines \\ Engineering | Physical Sciences and Mathematics \\ Publication Details \\ Zhang, H., Gu, Q., Wallace, G. G. \& Higgins, M. J. (2018). Effect of electrochemical oxidation and reduction \\ on cell de-adhesion at the conducting polymer-live cell interface as revealed by single cell force \\ spectroscopy. Biointerphases: an open access journal for the biomaterials interface community, 13 (4), \\ 041004-1-041004-13.
}

This journal article is available at Research Online: https://ro.uow.edu.au/aiimpapers/3172 


\section{Effect of electrochemical oxidation and reduction on cell de-adhesion at the conducting polymer-live cell interface as revealed by single cell force spectroscopy}

Cite as: Biointerphases 13, 041004 (2018); https://doi.org/10.1116/1.5022713

Submitted: 17 January 2018 . Accepted: 11 May 2018. Published Online: 11 June 2018

Hongrui Zhang, Qi Gu, Gordon G. Wallace, and Michael J. Higgins

COLLECTIONS

F This paper was selected as Featured
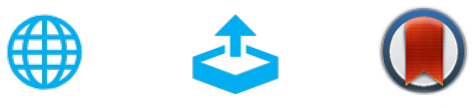

\section{ARTICLES YOU MAY BE INTERESTED IN}

Effect of monophasic pulsed stimulation on live single cell de-adhesion on conducting polymers with adsorbed fibronectin as revealed by single cell force spectroscopy

Biointerphases 14, 021003 (2019); https://doi.org/10.1116/1.5082204

Role of ionic strength in the retention and initial attachment of Pseudomonas putida to quartz sand

Biointerphases 13, 041005 (2018); https://doi.org/10.1116/1.5027735

Bioinspired, nanoscale approaches in contemporary bioanalytics (Review)

Biointerphases 13, 040801 (2018); https://doi.org/10.1116/1.5037582

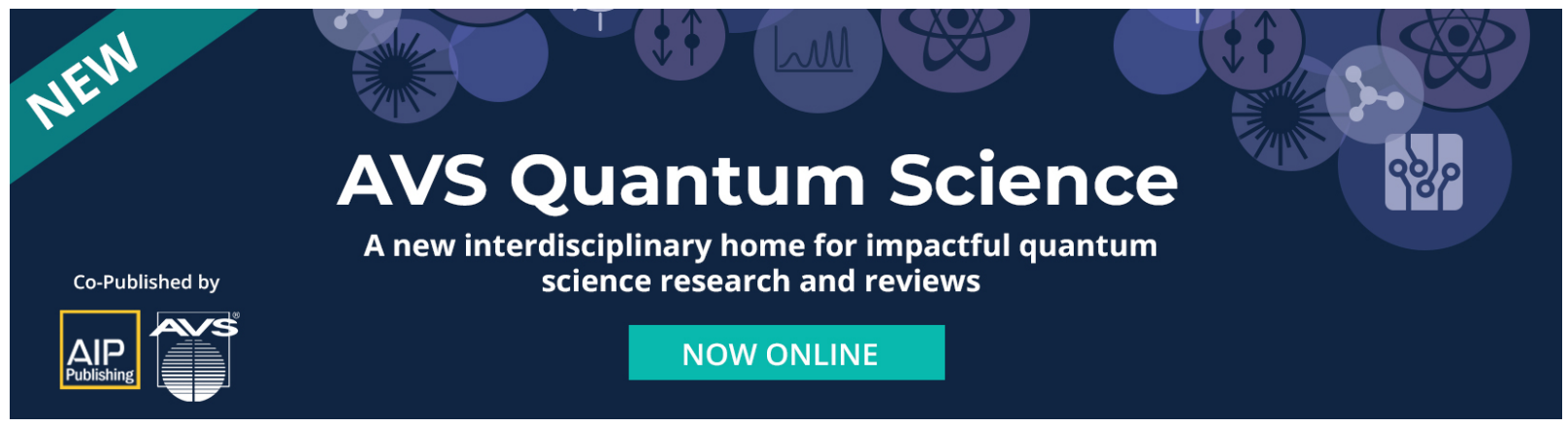




\title{
Effect of electrochemical oxidation and reduction on cell de-adhesion at the conducting polymer-live cell interface as revealed by single cell force spectroscopy
}

\author{
Hongrui Zhang, ${ }^{1}$ Qi Gu, ${ }^{1,2}$ Gordon G. Wallace, ${ }^{1}$ and Michael J. Higgins ${ }^{1, a)}$ \\ ${ }^{1}$ ARC Centre of Excellence for Electromaterials Science, Intelligent Polymer Research Institute, AIIM Facility, \\ Innovation Campus, Squires Way, University of Wollongong, Wollongong, New South Wales 2522, Australia \\ ${ }^{2}$ State Key Laboratory of Membrane Biology, Institute of Zoology, Chinese Academy of Sciences, Beijing \\ 100101, China
}

(Received 17 January 2018; accepted 11 May 2018; published 11 June 2018)

Cell adhesion on conducting polymers is important in organic bioelectronics, including applications such as electronically switchable surfaces and electrochemical transistors. There is a fundamental interest in understanding the conducting polymer-cellular interface though as yet no direct measurements to quantify the cell adhesion forces and energies, particularly at the molecular level, have been undertaken. Here, the authors apply electrochemical-single cell force spectroscopy (EC-SCFS) to directly quantify the de-adhesion forces between single L929 fibroblast cells and polypyrrole doped with dodecylbenzene sulfonate (PPy-DBSA) under electrical stimulation. The EC-SCFS reveals single cell de-adhesion forces of $0.65 \mathrm{nN}$ on PPy-DBSA films with adsorbed fibronectin (FN) protein. Blocking experiments by introducing antibodies show that cell de-adhesion is largely due to the binding ( $60 \%$ of interactions) of cell-surface $\alpha 5 \beta 1$ integrin receptors. Electrochemical oxidation and reduction of PPy-DBSA during initial adsorption of fibronectin cause a significant decrease in the single cell de-adhesion forces to $\sim 0.4 \mathrm{nN}$, which is suggested to relate to electrical stimulation effects on reducing FN adsorption on the polymer. In contrast, when electrical stimulation is applied after protein adsorption is established and during the EC-SCFS measurements, the single cell de-adhesion is significantly enhanced on the oxidized polymer compared to the reduced and nonbiased polymer. The study highlights the use of EC-SCFS to directly quantify cell adhesion on electrode surfaces, as well as the ability to probe molecular-level interactions such as integrin receptor-FN complexes with forces of $\sim 50-100 \mathrm{pN}$. Published by the AVS. https://doi.org/10.1116/1.5022713

\section{INTRODUCTION}

The bioengineering of surfaces, materials, and polymers is increasing in complexity from a static two-dimensional spatial presentation of functional groups, ligands, and polymer brushes to temporal control of surface properties in a time-dependent manner that mimics the native cellular environment and provides opportunities in tissue engineering and regenerative medicine. ${ }^{1-5}$ Stimuli-responsive materials are critical to this research, and by applying external signals such as light, heat, and electrical fields, their material properties such as wettability, modulus, porosity, and functional groups can undergo dynamic and reversible changes for "on-demand" control of cell interactions. ${ }^{6-8}$ By dynamically cleaving or blocking covalently linked cell binding peptides, the cell adhesion can be switched on or off, ${ }^{9-11}$ which provides instructional cues via the material for cell growth and development.

Here, we focus on electrically switchable organic conducting polymers that are capable of electrochemically inducing several dynamic and biomolecular processes, including enhancing cell proliferation or differentiation, ${ }^{12-14}$ release of growth factors or drugs, ${ }^{15-17}$ cleaving or attracting/repelling

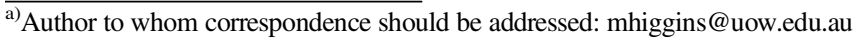

surface functional groups, modifying protein adsorption and conformation, and switching of cell adhesion. ${ }^{18-23}$ Several studies on controlling cell adhesion have sought to elucidate the effect of electrochemically driven changes in the interfacial properties, including $p \mathrm{H}$, charge, and wettability, on the adsorbed extracellular matrix proteins that mediate cell adhesion. ${ }^{23-26}$ Electrical effects on the surface adsorbed proteins, such as changes in protein density, orientation, or conformation, are often used to extrapolate to mechanisms underlying the changes in cell morphology and adhesion, e.g., rounding up or spreading of cells. The mechanisms of cell recognition and detachment from conducting polymers with adsorbed protein layers are not well understood, yet such information is critical in different feedback mechanisms involved in cell adhesion-mediated signaling on material surfaces. ${ }^{27}$ To date, there have been no direct measurements to quantify the degree of cell adhesion and associated molecular interactions, particularly the energies and forces, between the living cell surface and conducting polymer during electrical switching.

Optical techniques are typically used to observe the live cell adhesion, including processes such as cell spreading or detachment. Alternatively, observations are made by fluorescent labeling cell adhesion molecules and adhesion complexes, i.e., focal adhesions, of chemically fixed cells. 
The presence of opaque or quenching materials, however, may not be compatible with high resolution or fluorescence observations, while getting direct access to the cell-material interface to probe molecular, physicochemical interactions in real-time is challenging using conventional techniques. Further complex design of stimuli-responsive materials is hampered by this lack of molecular-level monitoring and analysis. To address this, we implement an atomic force microscopy (AFM)-based approach, termed single cell force spectroscopy (SCFS), ${ }^{28-30}$ and combine this with in situ electrochemical-AFM (EC-AFM) to directly measure the adhesion forces required to detach single living cells from a conducting polymer substrate with surface adsorbed fibronectin (FN) and in real-time during electrical stimulation [Figs. 1(a) and 1(b)]. SCFS is an established technique that is increasingly used to measure single cell and receptor interactions extracellular matrix protein, ${ }^{31,32}$ cell-cell interactions, ${ }^{33}$ and cell interactions with chemically functionalized surfaces and materials. ${ }^{34-36}$ More recently, SCFS studies have been used to study the effect of electrical fields ${ }^{36,37}$ and photoswitching of surfaces on cell adhesion. ${ }^{38}$ In contrast to conventional cell adhesion measurements that are typically conducted on cells that have established adhesion over longer time periods (e.g., in cell culture for $>30$ min up to hours/days), the SCFS enables contact times on the order of seconds up to several tens of minutes. ${ }^{32}$ On second timescales, single integrin bond complexes can form, and their unbinding is detected to probe initial cell recognition with a material surface. ${ }^{32,38}$ In this study, a single cell is attached onto a tipless AFM probe, ${ }^{29}$ which is brought into contact with the conducting polymer functioning as a working electrode in a 3-electrode electrochemical cell positioned under the AFM [Fig. 1(a)]. More specifically, the aim was to elucidate the interactions involved in shorter-term, initial stages of cell adhesion. During the SCFS measurements, antibodies specific to the $\alpha 5 \beta 1$ integrin receptor were introduced to investigate the role of this receptor in cell adhesion, and the AFM force curves were performed to determine the effect of electrochemical oxidation and reduction on single cell adhesion [Fig. 1(b)], including molecular-level interactions.

\section{MATERIALS AND METHODS}

\section{A. Electrochemical polymerization of conducting polymer}

The aqueous solution for electrochemical polymerization consisted of $0.2 \mathrm{M}$ pyrrole monomer (Merck) and $2 \mathrm{mg} / \mathrm{ml}$ sodium dodecylbenzene sulfonate (DBSA) in Milli-Q water (18.2 M $\Omega$ ). Polypyrrole-DBSA (PPy-DBSA) was polymerized galvanostatically at $0.10 \mathrm{~mA} / \mathrm{cm}^{2}$ for $10 \mathrm{~min}$ via an eDAQ EA161 potentiostat and recorder (eDAQ Pty Ltd.). The electrodeposition process was performed in a 3-electrode JPK electrochemical cell with the gold mylar as the working electrode (growing area $2 \mathrm{~cm}^{2}$ ), a platinum wire as the counter electrode and $\mathrm{Ag} / \mathrm{AgCl}$ as the reference electrode (DRIREF-2SH, World Precision Instruments). After growth, the films were washed with Milli-Q water, gently dried with $\mathrm{N}_{2}$, and kept in a desiccator until use.

\section{B. Cyclic voltammetry}

Cyclic voltammograms (CVs) were acquired using PPyDBSA as the working electrode with a scan rate of $100 \mathrm{mV} / \mathrm{s}$ in $\mathrm{CO}_{2}$ independent cell culture medium in the same EC cell as those used in SCFS experiments. Electrochemical potentials were recorded versus the $\mathrm{Ag} / \mathrm{AgCl}$ reference electrode (DRIREF-2SH, World Precision Instruments).

\section{Cell culture}

Mouse fibroblast L929 cell lines were originally sourced from ATCC (CCL-1TM). L929 cells were cultured in Dulbecco's modified Eagle's medium (DMEM) (12800017, Life Technology) supplemented with $10 \%$ fetal bovine serum (FBS) (10099141, Life Technology) and $3.7 \mathrm{~g} / 1$ $\mathrm{NaHCO}_{3}$ (S5761, Sigma). Cells were cultured at $37^{\circ} \mathrm{C}$ in a humidified, $5 \% \mathrm{CO}_{2}$ atmosphere (HERA cell 150, Thermo)

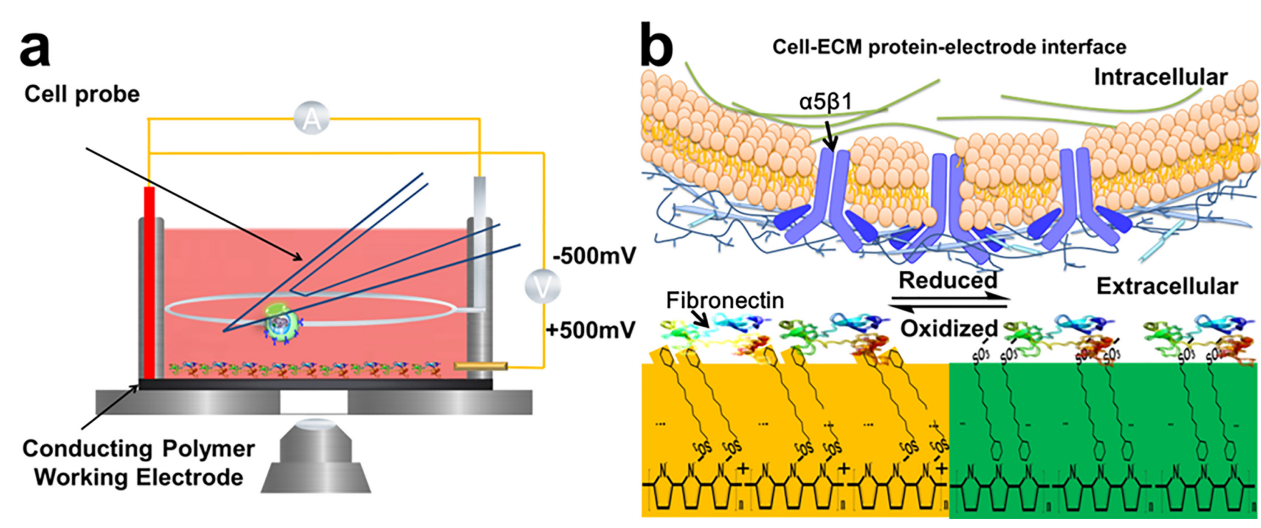

FIG. 1. (a) Schematic of SCFS combined with EC-AFM to quantify single live cell de-adhesion on a conducting polymer electrode with adsorbed protein as a function of electrical stimulation. The 3-electrode electrochemical cell is filled with the $\mathrm{CO}_{2}$ independent cell culture medium and controlled at $37{ }^{\circ} \mathrm{C}$, with the conducting polymer film as the working electrode, platinum ring as the counter electrode, and $\mathrm{Ag} / \mathrm{AgCl}$ as the reference electrode. (b) Zoomed in region of conducting polymer-cell interface. During the SCFS experiment, the PPy-DBSA electrode is electrochemically switched between the oxidized (yellow) and reduced (green) states, causing reorientation of the DBSA. The cell adhesion is mediated by adsorbed fibronectin on the conducting polymer electrode. 
and were subcultured every 2 days by splitting 1 in 10 after trypsinizing with $0.25 \%$ trypsin to achieve the desired cell density. Before the experiments, L929 cells were cultured to 90\%-100\% confluency of the cell culture flask. More specifically, old medium was removed from the cell culture flask and then rinsed with $5 \mathrm{ml}$ phosphate-buffered saline (PBS). To remove cells, trypsin $(0.25 \%, 0.5 \mathrm{ml})$ was added, and the cell culture flask was stored in a humidified $37^{\circ} \mathrm{C}$ incubator for 1-2 min. Five milliliters of fresh cell culture medium was then added to the flask, the cell suspension was transferred to a $15 \mathrm{ml}$ centrifuge tube and centrifuged at $1500 \mathrm{rpm}$ for $5 \mathrm{~min}$, and the supernatant was removed. Cells were then resuspended in $1 \mathrm{ml} \mathrm{CO}$ independent cell culture medium (18045-088, Life Technology) that is capable of maintaining long-term $p \mathrm{H}$ stability under atmospheric $\mathrm{CO}_{2}(0.04 \%)$ without proteins. One milliliter of the cell suspension was then transferred to $4 \mathrm{ml} \mathrm{CO}$ independent cell culture medium in a $15 \mathrm{ml}$ tube. One milliliter of the cell suspension was then injected into the AFM for SCFS experiments described below.

\section{Immunofluorescence staining of $\alpha 5 \beta 1$ integrin receptor}

To stain the $\alpha 5 \beta 1$ integrin receptor, L929 cells were cultured in a 12-well plate with a cover glass at the bottom of each chamber over $24 \mathrm{~h}$. After the cell culture medium (DMEM+10\%FBS) was removed, the cells were fixed with $3.7 \%$ paraformaldehyde (PFA) at room temperature for 10 min then permeabilized, and blocked with $0.3 \%$ Triton X-100 containing $10 \%$ donkey serum for $10 \mathrm{~min}$. The cells were incubated with an anti-integrin $\alpha 5 \beta 1$ antibody that is specific to $\alpha 5 \beta 1$ integrin receptor (Abcam, ab75472, http:// www.abcam.com/integrin-beta-5-antibody-ab15459.html) at room temperature for $1 \mathrm{~h}$. After the cells were rinsed with PBS three times, the samples were incubated with an Alexa Fluor secondary antibody (Invitrogen) at room temperature for another $1 \mathrm{~h}$. Finally, DNA was stained with 4',6-diamidino-2-phenylindole (DAPI, $10 \mu \mathrm{g} / \mathrm{ml}$ ). Afterwards, the coverslips were mounted onto glass sides and were observed under a scanning confocal system (Leica SP5).

\section{E. Immunofluorescence microscopy of FN-modified polymer}

FN immobilized PPy-DBSA films were fixed with $3.7 \%$ PFA for $10 \mathrm{~min}$, then gently washed with PBS, and incubated with a primary antibody, anti-fibronectin (Abcam, $\mathrm{AB} 2413,1: 200)$, for $30 \mathrm{~min}$ at room temperature. The samples were then gently washed with PBS followed by incubating with an Alexa Fluor 488-conjugated secondary antibody (Life Technologies, goat anti-rabbit IgG, 1:1000) at room temperature for $10 \mathrm{~min}$ and again washed with PBS. Observations were performed on a confocal microscope (Leica TSC SP5 II). Approximately five images were collected for each sample. Fluorescence densities for the images were analyzed using the Leica Application Suite Advanced Fluorescence software (Leica).

\section{F. AFM tipless cantilever functionalization with concanavalin-A}

AFM tipless probes (NP-O10 from Bruker) were firstly plasma cleaned for $20 \mathrm{~min}$ and then calibrated for their spring constant using the thermal method in air. ${ }^{39}$ The probes were incubated in $0.5 \mathrm{mg} / \mathrm{ml}$ biotin-bovine serum albumin (biotinamidocaproyl-labeled) (A6043, Sigma) for $12 \mathrm{~h}$ at $4{ }^{\circ} \mathrm{C}$. After rinsing with PBS (P5368, Sigma), the probes were incubated in $0.5 \mathrm{mg} / \mathrm{ml}$ streptavidin solution for $1 \mathrm{~h}$ at room temperature, followed by further rinsing with PBS. To enable covalent coupling of concanavalin-A (ConA), the probes were finally incubated in biotin-ConA (C2272, Sigma) for $1 \mathrm{~h}$ at room temperature and rinsed with PBS. After functionalization, the probes could be stored at $4{ }^{\circ} \mathrm{C}$ for up to 2 weeks.

\section{G. AFM tipless cantilever functionalization with single live cells}

As described above, $\mathrm{L} 929$ cells were resuspended in $\mathrm{CO}_{2}$ independent cell culture medium (18045-088, Life Technology) and $1 \mathrm{ml}$ was injected into the JPK Nanowizard Bio-AFM electrochemical cell, which was maintained at $37^{\circ} \mathrm{C}$. Cells were allowed to settle onto the PPy-DBSA film for only 5-10 min to ensure that they did not spread and adhere to the surface. A ConA functionalized AFM probe was lowered toward the surface, and prior to attaching a cell, an SCFS curve was performed on the polymer substrate to measure the sensitivity. The probe was then positioned over a cell, and contact was made with a force of $1 \mathrm{nN}$ for $5 \mathrm{~s}$ followed by retraction of the probe with an attached single cell. Visualization of both the cantilever and cell with the inverted microscope and control of the sample by a motorized stage with a step resolution of approximately $<0.5 \mu \mathrm{m}$ enabled precise positioning of a single cell at the end of the AFM cantilever. The cell was allowed to establish adhesion for 10-15 min on the ConA functionalized cantilever prior to the SCFS measurements. The latter is an important procedure for ensuring that cell adhesion to the cantilever is greater than adhesion to the opposing surface. The live cell probe was then repositioned over the polymer substrate to perform SCFS curves.

\section{H. Electrochemical-SCFS}

SCFS was performed using a JPK Nanowizard II mounted on a fully automated inverted Nikon microscope, with the 3-electrode electrochemistry cell integrated onto the AFM sample stage. The instrument was enclosed in a cell incubation system for temperature and humidity control. The electrochemical cell also enabled local temperature control of the sample and consisted of a freshly grown PPy-DBSA polymer film as the working electrode, a platinum wire as the counter electrode, and a small $\mathrm{Ag} / \mathrm{AgCl}$ reference electrode. Electrochemical voltage and current signals/recording were controlled via an Edaq potentiostat and recorder (eDAQ EA161). SCFS parameters included the use of 
constant height mode with a contact force of $0.5 \mathrm{nN}$, dwell-time of $1 \mathrm{~s}$, and retract speed of $5 \mu \mathrm{m} / \mathrm{s}$.

\section{Electrical stimulation schemes for electrochemical-SCFS}

\section{Electrical stimulation (1) "during" fibronectin deposition}

Human plasma $\mathrm{FN}$ was purchased from Invitrogen (Australia) (33016-015) and reconstituted in distilled water at a concentration of $1.0 \mathrm{mg} / \mathrm{ml}$. Twenty microliter aliquots of the $\mathrm{FN}$ solution were prepared in $2 \mathrm{ml}$ tubes and stored at $-80{ }^{\circ} \mathrm{C}$ until use. The aliquots were diluted to $20 \mu \mathrm{g} / \mathrm{ml}$ of FN by adding $1 \mathrm{ml}$ PBS solution and then used for coating the PPy-DBSA electrode. For FN deposition during electrical stimulation, the protein was injected into the electrochemical cell of the JPK Nanowizard Bio-AFM with the PPy-DBSA as the working electrode (growing area $2 \mathrm{~cm}^{2}$ ), a platinum wire as the counter electrode, and $\mathrm{Ag} / \mathrm{AgCl}$ as the reference electrode (DRIREF-2SH, World Precision Instruments). Immediately after injecting the $\mathrm{FN}$ solution, a constant voltage of +500 or $-500 \mathrm{mV}$ was applied for $5 \mathrm{~min}$, and after $1 \mathrm{~h}$, the FN-modified PPy-DBSA surfaces were then rinsed and fresh $\mathrm{CO}_{2}$ independent medium was added into the electrochemical cell for the SCFS experiments. FN-modified PPy-DBSA surfaces were also prepared without applying electrical stimulation during the FN adsorption. L929 cells were injected into the electrochemical cell followed by attachment of a live cell to the AFM probe. After positioning the live cell probe above the polymer substrate, ten SCFS curves were taken, and measurements were repeated with ten different cells on each of the different polymer surfaces. For this electrical stimulation scheme (1), SCFS curves were taken only after the FN had adsorbed, followed by rinsing and exchange with fresh media, and no electrical stimulation was applied during the SCFS curves.

\section{Electrical stimulation (2) "during" SCFS measurements}

FN modified PPy-DBSA surfaces were prepared without applying electrical stimulation as described above and placed into the electrochemical cell. L929 cells were then injected into the electrochemical cell, and preparation of a live cell to the AFM probe was performed, followed by the SCFS experiments. After positioning the live cell probe above the polymer substrate, ten SCFS curves were firstly performed on the conducting polymer with no applied potential. The live cell probe was then retracted for $50 \mu \mathrm{m}$, and a constant voltage was applied. SCFS curves resumed once the current had reached steady state ( $30 \mathrm{~s})$ and were performed during the electrical stimulation. This procedure was performed on the same live probe for the nonbiased polymer followed by applied potentials of +500 and $-500 \mathrm{mV}$. Ten SCFS curves were collected on each of the different surfaces. Thus, a total of 30 curves were collected for each cell. Measurements were repeated with ten different cells and PPy-DBSA polymer films.

\section{J. Integrin blocking experiments}

Anti-integrin $\alpha 5 \beta 1$ antibody (ab75472, Abcam) was aliquoted $(2 \mu \mathrm{l})$ into $2 \mathrm{ml}$ tubes and stored at $-80{ }^{\circ} \mathrm{C}$ prior to use. After pipetting out $1 \mathrm{ml}$ of the cell suspension, the cells were then injected into the aliquot of antibody. One milliliter of the cell suspension with the anti-integrin $\alpha 5 \beta 1$ antibody was then transferred to a $15 \mathrm{ml}$ tube, and $4 \mathrm{ml}$ of fresh $\mathrm{CO}_{2}$ independent medium was added. The $5 \mathrm{ml}$ cell suspension with the antibody was kept at $37^{\circ} \mathrm{C}$ in an incubator for 30 min before injecting into 3-electrode EC-AFM cells for the blocking experiments. Using these cells, the blocking measurements were repeated for both electrical stimulation schemes (1) and (2), as described above for the SCFS.

\section{K. Data analysis}

SCFS curves were analyzed using the JPK-SPM Data Processing software (version spm-5.1.4). The raw curves were firstly converted to force versus distance curves and then modified to adjust the baseline offset and arbitrary contact point. The software automated the measurement of the maximum de-adhesion force (maximum negative force value) and de-adhesion energy (integrated area under negative force region) and also enabled detection of the individual ruptures, including jumps and plateaus. Fit parameters for identifying and quantifying the jumps and plateaus were controlled by smoothing $(<4.0)$ and significance $(0.005)$ parameters, and their identification was subsequently confirmed by manual checking. More specifically, jumps were categorized as those ruptures with only negative slopes greater than $-20 \mathrm{pN} / \mu \mathrm{m}$ while plateaus with slopes in the positive region close to zero, i.e., $0-20 \mathrm{pN} / \mu \mathrm{m}$ were only considered for the analysis, according to similar analysis done by Sariisik et $a l^{40}$ Box-and-whisker plots of the maximum de-adhesion, de-adhesion energy, jump/plateau force, and length were plotted and fitted by OriginPro 9.1. To account for changes in cell modulus on adhesion, we fitted the contact region of the approaching curves to contact mechanical (hertz) model using the JPK Data Processing software (version spm-5.1.4) to quantify Young's modulus of the cells as a function of the series of applied voltages applied to the polymer.

\section{RESULTS AND DISCUSSION}

\section{A. Electrical stimulation schemes of conducting polymer}

Using the in situ EC-AFM, CV measurements acquired in $\mathrm{CO}_{2}$ independent culture medium show the electroactivity of the PPy-DBSA substrate, including clear oxidation and reduction potentials of -340 and $-500 \mathrm{mV}$, respectively, when cycling the applied voltage from +0.5 to $-1.0 \mathrm{~V}$ [Fig. 2(a)]. Constant potentials of +500 and $-500 \mathrm{mV}$ were applied to oxidize and reduce the polymer electrode for the SCFS measurements [Fig. 2(b)]. The induced current under $-500 \mathrm{mV}$ was greater than $+500 \mathrm{mV}$, and both current signals decreased and stabilized near the zero baseline 

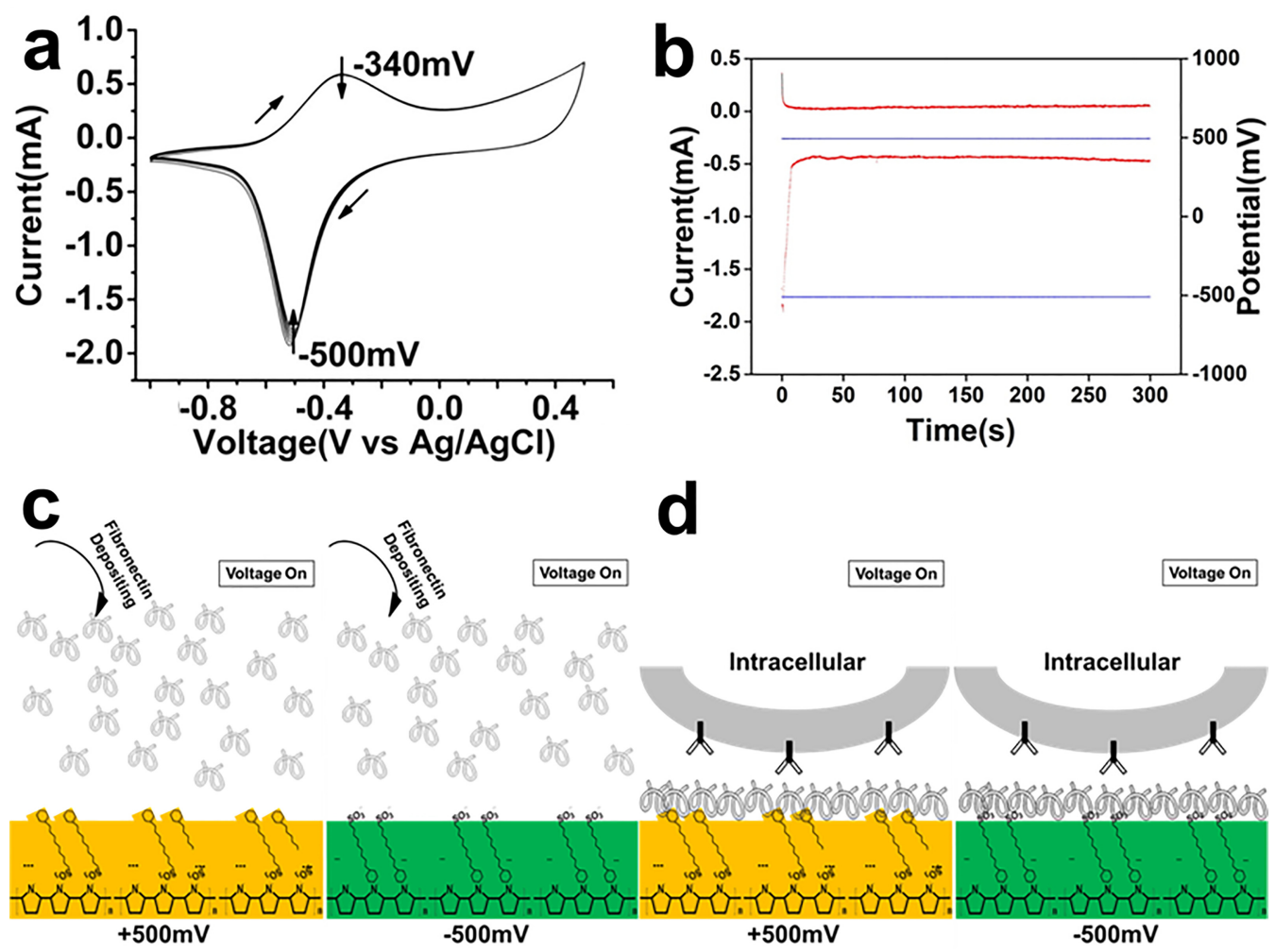

FIG. 2. (a) Cyclic voltammetry (CV) of PPy-DBSA polymer in the $\mathrm{CO}_{2}$ independent cell culture medium with a scan rate of $100 \mathrm{mV} / \mathrm{s}$ and potential window of +0.8 to $-1.0 \mathrm{~V}$. All potentials are reported vs $\mathrm{Ag} / \mathrm{AgCl}$. (b) Current (red) and corresponding potentials of +500 and $-500 \mathrm{mV}$ (blue) vs time (s) signals that are applied for the EC-SCFS. (c) Schematic of electrical stimulation scheme (1) for applying a potential of either +500 or $-500 \mathrm{mV}$ as shown in (b) during adsorption of fibronectin protein onto the PPy-DBSA. (d) Schematic of electrical stimulation scheme (2) for applying a constant potential of either +500 or $-500 \mathrm{mV}$ as shown in (b) after fibronectin protein is established and simultaneously during the SCFS measurements between a single living L929 fibroblast cell and PPy-DBSA.

current within $<10 \mathrm{~s}$ [Fig. 2(b)]. The higher induced current and baseline value for $-500 \mathrm{mV}$ were also reflected in the $\mathrm{CV}$ measurements. During electrical stimulation, the redox switching mechanism for PPy-DBSA involves rearrangement of the sulfonate and dodecylbenzene groups of the DBSA molecules within the conducting polymer. ${ }^{41}$ During oxidation (yellow), the negatively charged sulfonate groups coordinate with the positively charged polymer, causing the hydrophobic groups to orientate to the polymer-liquid interface [Fig. 1(b)]. The sulfonate groups and hydrophobic groups can then switch orientation during reduction (green), with the hydrophobic groups preferring to coordinate with the neutral polymer backbone [Fig. 1(b)]. The SCFS measurements were undertaken in the presence of adsorbed FN protein on the conducting polymer substrate. Two different schemes of the electrical stimulation were applied for the SCFS measurements [Figs. 2(c) and 2(d)]: firstly, scheme (1) where a constant voltage of either +500 or $-500 \mathrm{mV}$ was applied only during adsorption of $\mathrm{FN}$ onto the polymer surface and switched off during the SCFS measurements [Fig. 2(c)] and secondly, scheme (2) where a constant voltage of $+500 \mathrm{mV}$ followed by $-500 \mathrm{mV}$ was applied after protein adsorption had been established and during the SCFS measurements, i.e., detachment of the cell from the surface [Fig. 2(d)].

\section{B. Specificity of $\alpha 5 \beta 1$ integrin binding during cell adhesion (blocking experiments)}

Without an applied voltage, SCFS curves measuring the de-adhesion forces between a single L929 fibroblast cell and PPy-DBSA with adsorbed FN showed hysteresis upon retraction of the cell from the surface (red curve). The hysteresis consists of a large peak related to the approximately nanonewton forces required to detach most of the cells from the surface, followed by smaller peaks and plateaus of approximately $<100 \mathrm{pN}$ [Fig. 3(a)], previously defined as jumps and tethers. ${ }^{29}$ The largest peak value is defined as the maximum de-adhesion force, while the de-adhesion energy required to fully detach the cell from the surface is given as the integrated area under the curve (red striped area). The adsorbed FN layer is known to specifically bind integrins, including $\alpha 5 \beta 1$, $\alpha \operatorname{IIb} \beta 3$, and $\alpha v \beta 3{ }^{42}$ The integrin, $\alpha 5 \beta 1$, is considered to be a prototype receptor of FN, specialized for binding to FN via the RGD and PHSRN regions, and one of the majorly expressed FN receptors across many cell types, ${ }^{43}$ including the L929 cell line. ${ }^{44}$ To elucidate the involvement of the FN binding to $\alpha 5 \beta$ 1integrin, blocking experiments were performed by undertaking the SCFS measurements in the presence of an anti-integrin $\alpha 5 \beta 1$ antibody. Suppression of the de-adhesion forces by the antibody indicates the 

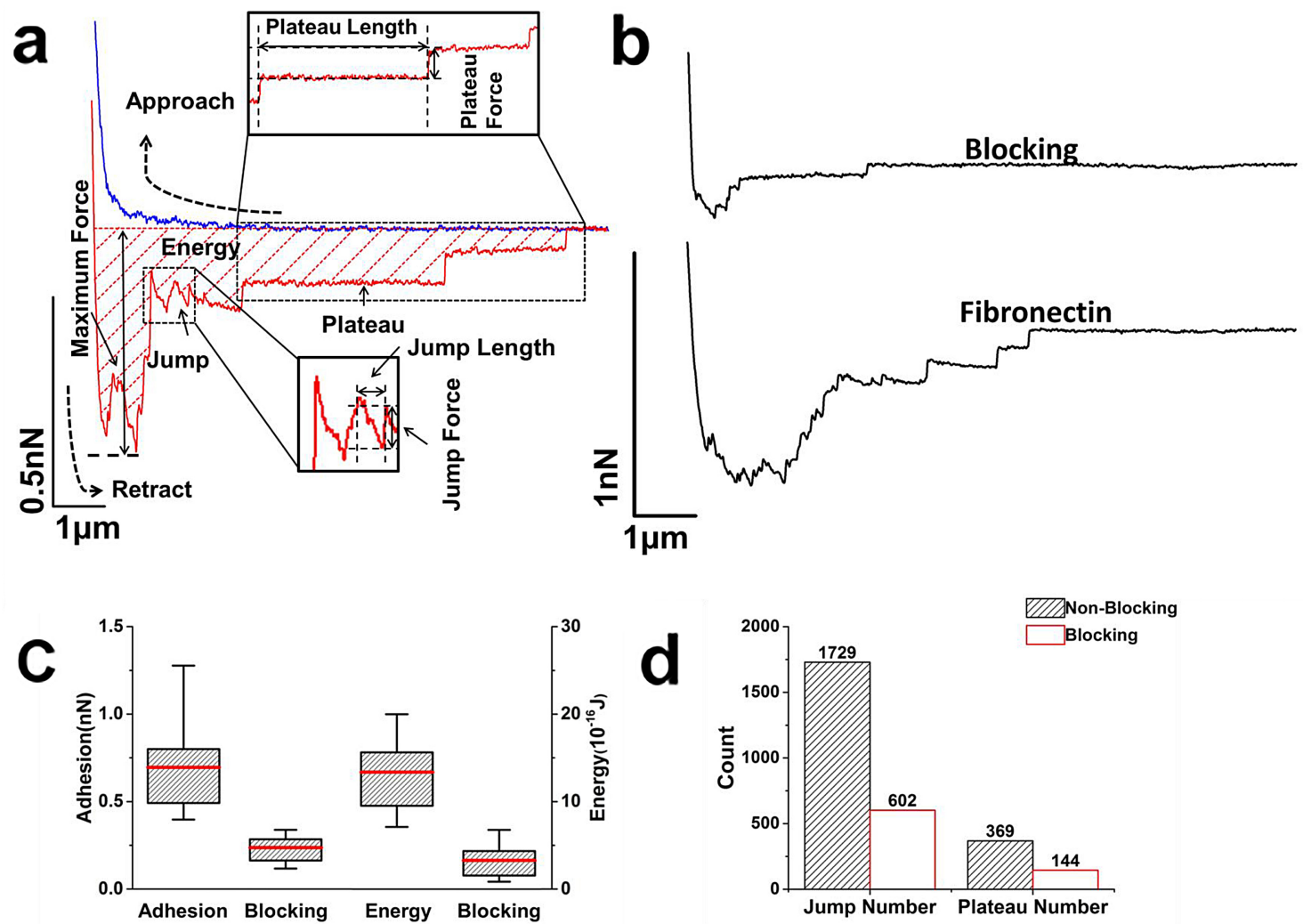

FIG. 3. (a) Representative SCFS curve for interaction between a single live L929 cell on a nonbiased (control) PPy-DBSA film with adsorbed fibronectin protein. Blue and red curves are the approach and retraction, respectively. In the retraction curve, the maximum force value corresponds to the de-adhesion force, and red striped region corresponds to the total energy or work of cell detachment from the PPy-DBSA. After initial de-adhesion, SCFS curves consist of jump and plateau interactions, which are analyzed to quantify their individual forces and lengths. (b) (Bottom curve) Representative SCFS curve for the interaction between a single live L929 cell and nonbiased (control) PPy-DBSA with adsorbed fibronectin protein. (Top curve) Representative SCFS curve for blocking experiments using anti-integrin $\alpha 5 \beta 1$ antibodies to bind cell $\alpha 5 \beta 1$ integrin receptors. (c) Box-and-whisker plots showing de-adhesion forces and energy and those corresponding values obtained after blocking experiments on nonbiased PPy-DBSA with adsorbed fibronectin protein. (d) Bar chart showing the total number of jump and plateau events per force curve for the interaction between a single live L929 cell and nonbiased (control) PPy-DBSA with adsorbed fibronectin protein (black striped). Corresponding values for blocking experiments are shown in red bars. Measurements are analyzed from 100 SCFS curves for each group.

binding specificity of the receptor during the cell adhesion. The SCFS curves with blocking showed a significant decrease in the maximum de-adhesion force and energy [Fig. 3(b)], indicating that the $\alpha 5 \beta 1$ receptor was involved in adhesion between the cell and PPy-DBSA with adsorbed FN. Maximum de-adhesion force of $0.65 \pm 0.2 \mathrm{nN}$ without antibody decreased by more than $50 \%$ to $0.30 \pm 0.1 \mathrm{nN}$, while the de-adhesion energy of $(12.9 \pm 0.7) \times 10^{-16} \mathrm{~J}$ decreased by $\sim 80 \%$ to $(2.8 \pm 0.2) \times 10^{-16} \mathrm{~J}$ [Fig. 3(c)]. The number of rupture events associated with jump and plateau interactions decreased by $60 \%-65 \%$ during blocking experiments [Fig. 3(d)], indicating that these events were primarily due to $\alpha 5 \beta 1-\mathrm{FN}$ binding. The presence of the $\alpha 5 \beta 1$ integrin was further shown by immunofluorescence anti-integrin $\alpha 5 \beta 1$ antibody staining that shows a high expression level of this receptor on the L929 cell surface [Fig. 4(c)]. Despite confirming the specific $\alpha 5 \beta 1-F N$ binding, a de-adhesion force of $0.30 \pm 0.1 \mathrm{nN}$ remained after blocking. This residual adhesion is likely due to additional FN binding to other integrins expressed on the cell surface that are not blocked and/or from prevailing nonspecific interactions with the cell membrane, as shown in our previous SCFS study. ${ }^{36}$ For the purpose of this study, we investigated only the $\alpha 5 \beta 1$ integrin receptor, as opposed to several expressed integrins, ${ }^{45}$ to confirm the extent of interactions with the adsorbed FN. Lastly, the presence of adsorbed FN caused a significant increase in the maximum de-adhesion force $(0.65 \pm 0.2 \mathrm{nN})$ and energy $\left[(12.9 \pm 0.7) \times 10^{-16} \mathrm{~J}\right]$ in comparison to our previous study where the $\mathrm{L} 929$ cell de-adhesion force $(0.54 \pm 0.2 \mathrm{nN})$ and energy $\left[(9.5 \pm 0.4) \times 10^{-16} \mathrm{~J}\right]$ were measured only on the PPy-DBSA without adsorbed FN. ${ }^{36}$

\section{Effects of electrical stimulation on single cell de-adhesion force and energy}

\section{Electrical stimulation scheme (1)}

Oxidation and reduction of the polymer by applying a constant voltage of either +500 or $-500 \mathrm{mV}$ only during FN adsorption significantly reduced the cell de-adhesion forces compared to the nonbiased polymer. This was qualitatively 


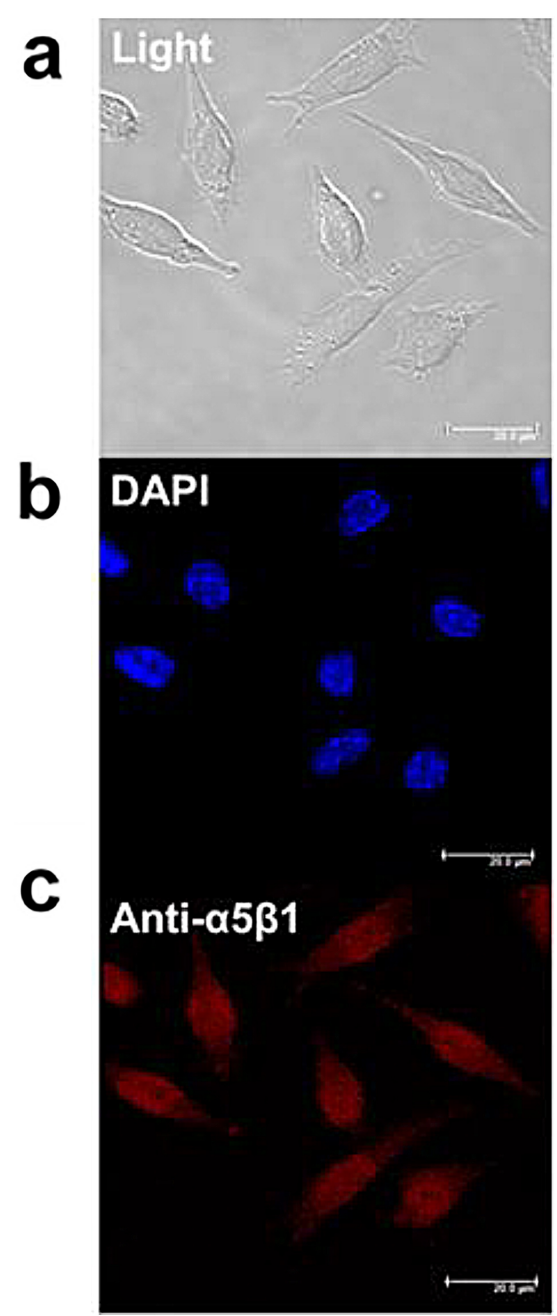

FIG. 4. Immunofluorescence stained images of L929 cells. (a) Light microscope image of L929 cells on a glass slide. (b) Fluorescence image of cell nuclei (blue) stained with DAPI. (c) Fluorescence image of cell-surface $\alpha 5 \beta 1$ integrin receptors (red) stained with anti-integrin $\alpha 5 \beta 1$ antibody.

observed in representative SCFS curves that showed that the nonbiased polymer (black curves) had higher de-adhesion force and energy compared to the electrically stimulated polymers (red and blue curves) [Fig. 5(a)]. Statistical analysis using box-and-whisker plots showed that the de-adhesion force for both $+500 \mathrm{mV}(0.37 \pm 0.1 \mathrm{nN})$ and $-500 \mathrm{mV}(0.40 \pm 0.1 \mathrm{nN})$ was significantly reduced compared to the nonbiased polymer $(0.65 \pm 0.2 \mathrm{nN})$ [Fig. 5 (b)]. No significant difference was observed between the two applied voltages.

This effect of oxidation and reduction during FN adsorption on the cell adhesion does not correlate to surface energies of the conducting polymer. For instance, oxidation of PPy-DBSA results in increasing surface hydrophobicity due to interfacial switching of the dodecylbenzene groups, ${ }^{41}$ producing a contact angle of $64^{\circ} .{ }^{36}$ Conversely, the reduced polymer is more hydrophilic with contact angles of $\sim 20^{\circ}-50^{\circ 36}$ yet gives de-adhesion forces and energies comparable to the oxidized film. Furthermore, the nonbiased polymer, which is effective in the oxidized state with contact angles $\left(78^{\circ}\right)$ closer to the oxidized film, ${ }^{36}$ gives significantly higher de-adhesion forces and energy than both electrically stimulated films.

To alternatively understand the possible effects of the adsorbed FN, immunofluorescence labeling with an Alexa Fluor 488-labeled anti-fibronectin antibody showed a fluorescence intensity of $11.1 \pm 0.5$ (background signal) for the PPy-DBSA surface without FN (control), which significantly increased to $58.5 \pm 1.2$ after FN adsorption. For polymers with applied potentials of +500 and $-500 \mathrm{mV}$, the fluorescence intensity showed significantly lower values of $31.3 \pm 1.6$ and $32.5 \pm 1.2$, respectively, suggesting that the degree of protein adsorption was diminished by electrical stimulation. However, changes in FN conformation are also known to inhibit access for binding of the anti-fibronectin antibody, leading to decreases in fluorescence intensity. Based on these observations, we suggest that the significant decrease in de-adhesion force and energy is due to the stimulated polymers, both +500 and $-500 \mathrm{mV}$, that reduced protein adsorption but cannot unequivocally exclude effects from changes in the FN conformation.

Further statistical analysis of the de-adhesion energy, or work required to detach the cell, revealed a more complete view of the cell adhesion [Fig. 5(c)]. For instance, the de-adhesion energy for $-500 \mathrm{mV}\left[(12.4 \pm 0.7) \times 10^{-16} \mathrm{~J}\right]$ was significantly higher than that of $+500 \mathrm{mV}\left[(7.8 \pm 0.6) \times 10^{-16} \mathrm{~J}\right]$ despite the two applied potentials showing comparable de-adhesion forces. Furthermore, the de-adhesion energies of the $-500 \mathrm{mV}\left[(12.4 \pm 0.7) \times 10^{-16} \mathrm{~J}\right]$ and nonbiased $[(12.9 \pm$ $\left.0.7) \times 10^{-16} \mathrm{~J}\right]$ polymers were not significantly different [Fig. 5(c)], yet the latter showed significantly higher de-adhesion forces [cf. in Fig. 5(b)]. Higher de-adhesion energies on the $-500 \mathrm{mV}$ polymer are correlated to a higher prevalence of plateau interactions [see Fig. 7(f)], which are observed to extend out to distances of $\sim 8-9 \mu \mathrm{m}$ [Fig. 5(a), curve $\mathrm{V}]$ and thus contribute to increased energy. Plateau interactions have previously been attributed to ligand-receptor complexes that have weak association with the internal cytoskeleton, ${ }^{29,30,32}$ enabling the formation of membrane tubes, or tethers, that can extend for several micrometers and reported to play a role in adhesion of neutrophils to platelets. $^{46}$

Changes in the mechanical properties of the cells may also contribute to increased energy during cell de-adhesion. It is possible that cells with lower stiffness can extend for greater distances under an applied tensile force. However, we did not observe a significant difference in Young's modulus of cells on the nonbiased and electrically stimulated polymers (Fig. 1 in the supplementary material ${ }^{57}$ ).

Alternatively, electrochemical reduction of polypyrrole is known to cause a significant increase in water uptake, ${ }^{36}$ potentially causing a decrease in the polymer stiffness and liberation of polymer chains ${ }^{41}$ thus potentially leading to longer-range interactions. Nevertheless, the exact reason for the increased plateau interactions on the $-500 \mathrm{mV}$ polymer is unclear though it is discussed further below. 
a
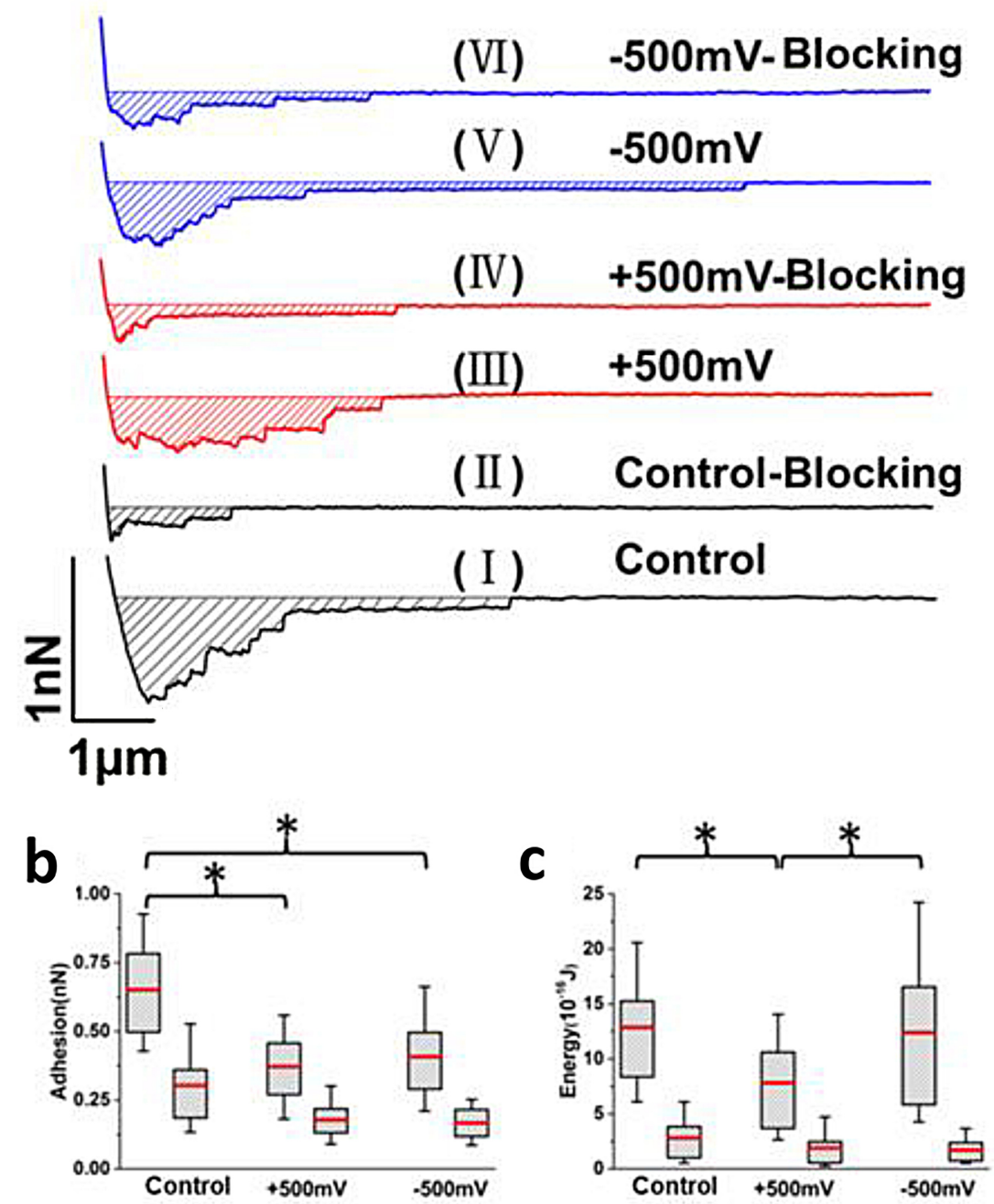

FIG. 5. (a) Electrical stimulation scheme (1) for constant voltages of either +500 or $-500 \mathrm{mV}$ that are applied only during FN adsorption. Representative SCFS curves are subsequently taken (with no applied potential) for the interaction between a live single L929 cell and PPy-DBSA surface with adsorbed FN. SCFS curves for $+500 \mathrm{mV}$ (red), $-500 \mathrm{mV}$ (blue), and nonbiased (control) PPy-DBSA (black) are shown along with the corresponding curves from the blocking experiments. (b) Box-and-whisker plots for de-adhesion forces (left box) and corresponding values for the blocking experiments (right box). (c) Box-and-whisker plots for de-adhesion energy (left box) and corresponding values for the blocking experiments (right box). The red line in the box-and-whisker plots marks the mean value. Asterisks indicate statistical significance values of $p<0.05$ (Mann-Whitney). All values in the main text are presented as mean \pm SEM, with at least ten cells analyzed and ten curves per cell (total curves $=100$ ).

\section{Electrical stimulation scheme (2)}

Analysis of the SCFS curves [Fig. 6(a)] shows that electrically switching from the oxidized to the reduced state during the SCFS and only after FN adsorption had already been established gives significantly higher de-adhesion forces for $+500 \mathrm{mV}(0.80 \pm 0.03 \mathrm{nN})$ and $-500 \mathrm{mV}(0.56 \pm$ $0.02 \mathrm{nN}$ ) compared to those of electrical stimulation scheme (1). Furthermore, the oxidized film showed a significant increase in the de-adhesion force and energy $[0.80 \pm 0.03 \mathrm{nN}$; $\left.(16.7 \pm 0.8) \times 10^{-16} \mathrm{~J}\right]$ compared to both the nonbiased $\left[0.70 \pm 0.03 \mathrm{nN} ;(13.4 \pm 0.7) \times 10^{-16} \mathrm{~J}\right]$ and reduced polymers $\left[0.56 \pm 0.02 \mathrm{nN} ;(13.2 \pm 0.9) \times 10^{-16} \mathrm{~J}\right]$ [Figs. 6(b) and 6(c)] .

These findings are discussed in relation to previous studies that showed epithelial cells adhered well to reduced poly(3,4-ethylenedioxythiophene doped with tosylate
(PEDOT/TOS) films while very few cells, mostly dead, remained on oxidized films when a bias voltage was applied immediately after cell seeding. ${ }^{22}$ The underlying cause of the cell viability on oxidized and reduced films was attributed to changes in the adsorbed serum layer, comprising mainly of FN and other proteins. ${ }^{22}$ However, if the cells were firstly allowed to settle on nonbiased films for $24 \mathrm{~h}$, followed by applying a bias voltage for $24 \mathrm{~h}$, both the reduced and oxidized films exhibited a large number of cells, suggesting that once cell adhesion was established switching their redox state did not affect cell viability. Further experiments showed that reduced PEDOT/TOS films gave an $\approx 3$ times increase in the number of adhered cells compared to oxidized films, leading to proposed theories that redox induced changes in the FN conformation either promote or inhibit access to cell 

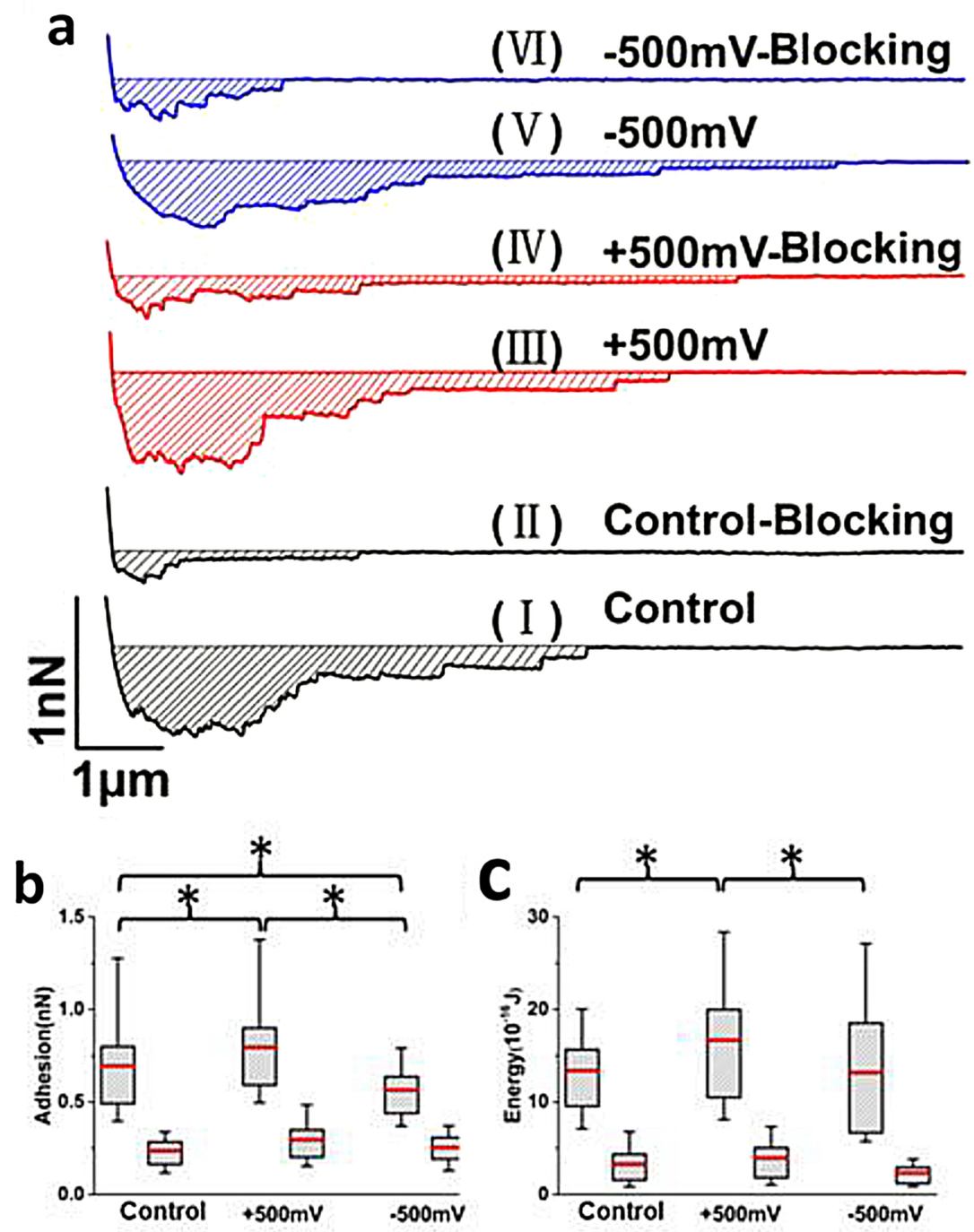

FIG. 6. (a) Electrical stimulation scheme (2) for constant voltages of either +500 or $-500 \mathrm{mV}$ that are applied after fibronectin adsorption and during the SCFS. Representative SCFS curves for $+500 \mathrm{mV}$ (red), $-500 \mathrm{mV}$ (blue), and nonbiased PPy-DBSA (control) (black) are shown along with the corresponding curves from the blocking experiments. (b) Box-and-whisker plots for de-adhesion forces (left box) and corresponding values for the blocking experiments (right box). (c) Box-and-whisker plots for de-adhesion energy (left box) and corresponding values for the blocking experiments (right box). The red line in the box-and-whisker plots marks the mean value. Asterisks indicate statistical significance values of $p<0.05$ (Mann-Whitney). All values in the main text are presented as mean \pm SEM, with at least ten cells analyzed and ten curves per cell (total curves $=100$ ).

binding regions. ${ }^{22}$ Earlier studies also alluded to this mechanism by explaining the rounding up and detachment of cells on oxidized $\mathrm{PPy} ;{ }^{47}$ however, other studies have since showed that oxidation of PEDOT/TOS conversely promoted the adhesion of mouse fibroblasts due to a higher affinity interaction between the $\alpha 5 \beta 1$ integrin and FN that was reportedly in a more folded conformation. ${ }^{24}$

Our results show that once FN adsorption was established on the PPy-DBSA surface, the cell de-adhesion forces and energy remained comparable to the nonbiased polymer despite the applied electrical stimulation [Figs. 6(b) and 6(c)]. Furthermore, by undertaking a direct measurement of cell de-adhesion forces, our electrochemical-SCFS (EC-SCFS) curves confirmed that the cells were more strongly attached during oxidation $(0.80 \pm 0.03 \mathrm{nN})$ compared to the reduced polymer $(0.56 \pm 0.02 \mathrm{nN})$ [Fig. 6(b)], with the de-adhesion energy values also giving the same trend [Fig. 6(c)]. In this case, by assuming that the mass of adsorbed FN on the oxidized and reduced polymer surface remains equivalent, i.e., fluorescence intensity $=58.1 \pm 1.2$, we suggest that the electrical stimulation affects the FN conformation, specifically causing an increase in cell adhesion on the oxidized polymer. This follows that FN was shown to adopt a folded conformation on oxidized PEDOT/TOS, which enhanced binding to $\alpha 5 \beta 1$ antibodies and was consistent with increased mouse fibroblast cell numbers on these polymers. ${ }^{24}$

This enhanced adhesion on the oxidized PPy-DBSA with exposed interfacial hydrophobic, dodecyl benzene groups may be considered contrary to the general rule that FN-mediated cell adhesion is favored by hydrophilic surfaces. Hydrophilic surfaces maintain a folded, bioactive conformation of FN, while hydrophobic surfaces denature the 


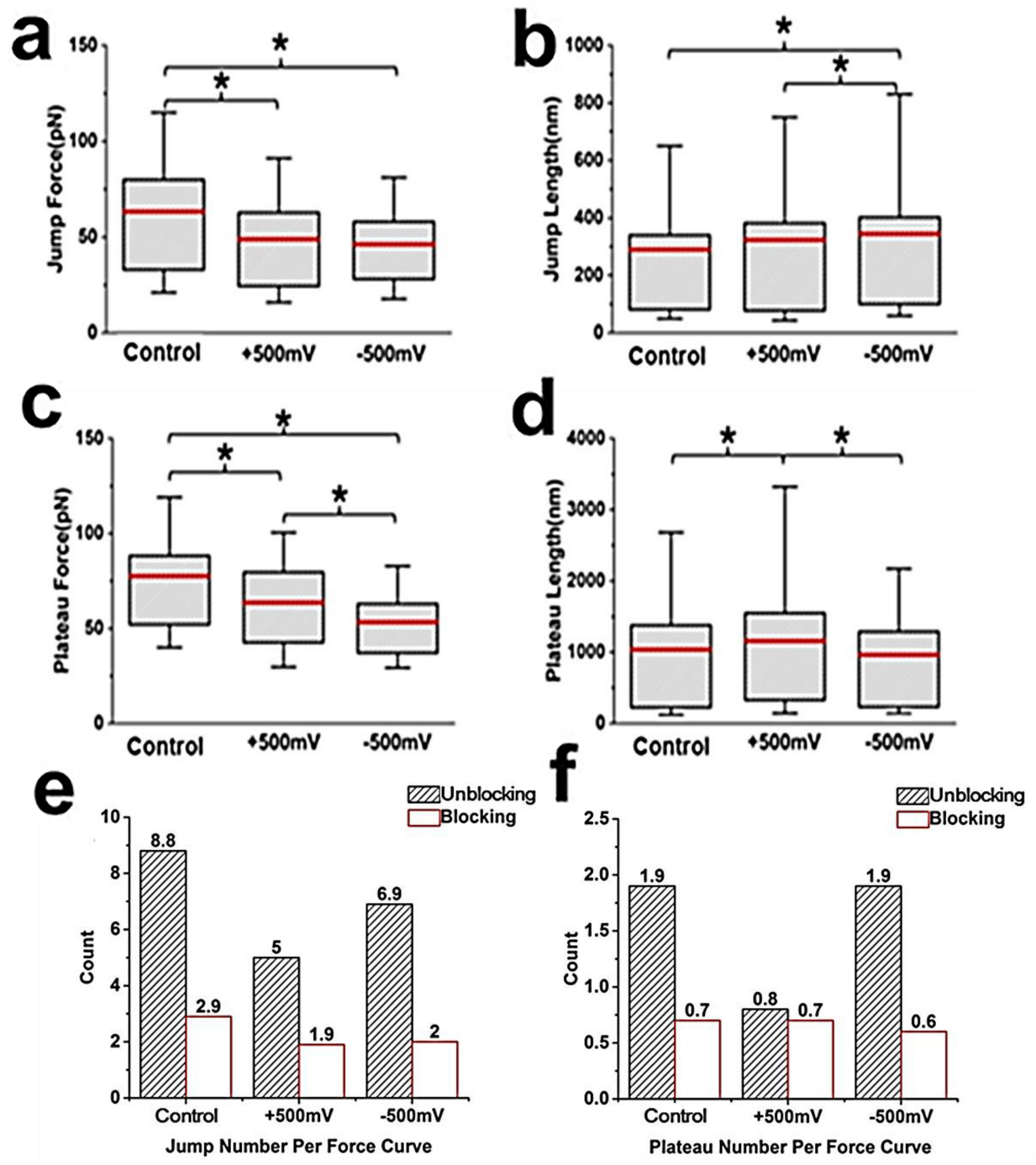

FIG. 7. Analysis of jump and plateau interactions [described in Fig. 3(a)] for electrical stimulation scheme (1). Box-and-whisker plots for (a) jump force, (b) jump length, (c) plateau force, and (d) plateau length of the $+500 \mathrm{mV},-500 \mathrm{mV}$, and nonbiased PPy-DBSA (control). The red line in the box-and-whisker plots marks the mean value. Asterisks indicate statistical significance values of $p<0.05$ (Mann-Whitney). All values in the main text are presented as mean \pm SEM, with at least ten cells analyzed and ten curves per cell (total curves $=100$ ). Bar charts for average number of (e) jumps and (f) plateaus per SCFS curve (black striped) and corresponding values for blocking experiments (red).

FN. ${ }^{48-50}$ That said, highly hydrophilic and/or sulfated polymers can also induce more extended or unfolded FN conformations, with increased hydration or flexibility to enable specific binding to a conducting polymer. ${ }^{25,51}$ It is noted that the oxidized PPy/DBSA remains moderately hydrophilic with a contact angle of $64^{\circ}$, and thus attributing the surface energy to effects on FN conformation is perhaps oversimplified for the complexity of the FN-polymer interaction, as discussed above. Furthermore, electrochemical switching the redox state of typical polymers such as PEDOT and PPy, including those with highly sulfated dopants, are not likely to fully switch between hydrophilic $\left(<90^{\circ}\right)$ and hydrophobic $\left(>90^{\circ}\right)$ surfaces but remain hydrophilic by definition of their contact angle. Alternatively, changes in the interfacial $p \mathrm{H}$ that are known to affect the $\mathrm{FN}$ conformation ${ }^{52}$ are proposed as another possible mechanism. For example, reduction of PEDOT/TOS drives protons into the polymer, decreasing proton density in the electrolyte and increasing the local $p \mathrm{H}$ $(p \mathrm{H}$ 7.7). FN adopts a more unfolded or extended conformation at higher $p \mathrm{H},{ }^{24}$ consistent with the reduced cell numbers on these polymers. During oxidation, the expulsion of protons from the polymer into the electrolyte, which is more negative, causes a lowering of $p \mathrm{H}(\mathrm{pH}$ 7.1) and leads to a more folded FN conformation and hence greater cell numbers. ${ }^{24}$ For comparison, the PPy/DBSA also expels cations (protons) during oxidation, while driving out cations during reduction. A mechanism based on changes in interfacial $p \mathrm{H}$ could then apply to the PPy/DBSA.

\section{Effect of electrical stimulation on molecular-level interactions (jumps and plateaus)}

Blocking agents such as free RGD in solution or fluorescently labeled antibodies are typically used to probe FN 

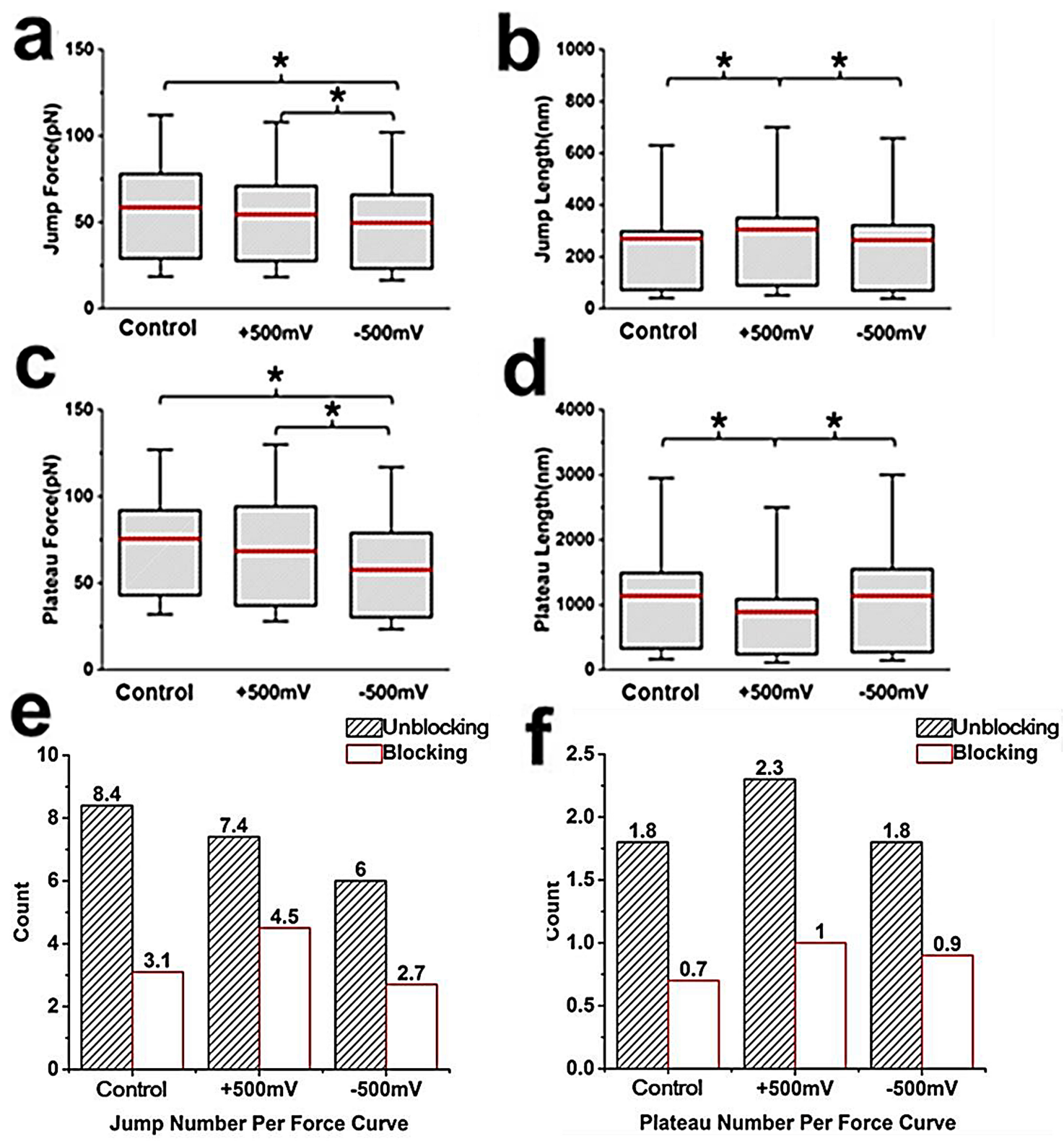

FIG. 8. Analysis of jump and plateau interactions [described in Fig. 3(a)] for electrical stimulation scheme (2). Box-and-whisker plots for (a) jump force, (b) jump length, (c) plateau force, and (d) plateau length of the $+500,-500 \mathrm{mV}$, and nonbiased PPy-DBSA (control). The red line in the box-and-whisker plots marks the mean value. Asterisks indicate statistical significance values of $p<0.05$ (Mann-Whitney). All values in the main text are presented as mean \pm SEM, with at least ten cells analyzed and ten curves per cell (total curves $=100$ ). Bar charts for average number of (e) jumps and (f) plateaus per SCFS curve (black striped) and corresponding values for blocking experiments (red).

binding to explain the cell adhesion on oxidized and reduced PEDOT. ${ }^{24}$ However, antibodies can bind several epitopes and may be insensitive to conformational changes or specific sites of the FN. ${ }^{24}$ Alternatively, the SCFS directly probes the ability of cell-surface receptors to access the protein binding motifs. ${ }^{53}$ In particular, analysis of individual jumps and plateaus can be indicative of single molecule ligand-receptor complexes, as previously reported. ${ }^{30,32}$ The cell-surface contact times are kept short, e.g., $\lesssim 1 \mathrm{~s}$, to facilitate binding with only a few or single receptors that can be isolated for analysis. ${ }^{29}$ However, we found that even when applying contact times of $1 \mathrm{~s}$ and low forces of $500 \mathrm{pN}$, the SCFS curves still showed a significant number of jumps, making analysis of single, isolated events not feasible. Thus, the jump/plateaus represented multiple interactions, e.g., unbinding of several receptors. In addition, despite the blocking showing the preponderance of the $\alpha 5 \beta 1$ integrin receptor accounting for $\sim 60 \%$ of the jump events, we could not exclude contributions from other receptors or nonspecific interactions. Despite these limitations, an analysis of all ruptures and plateaus that only showed a discrete event such as those described in Fig. 3(a) was undertaken to understand the effect of electrical switching on cell de-adhesion occurring at the molecular level. 


\section{Electrical stimulation scheme (1)}

For electrical stimulation during FN adsorption, the SCFS measurements showed comparable jump forces for $+500 \mathrm{mV}$ $(48.8 \pm 1.2 \mathrm{pN})$ and $-500 \mathrm{mV}(46.1 \pm 0.8 \mathrm{pN})$, both of which were significantly lower than those for the nonbiased polymer $(63.3 \pm 1.5 \mathrm{pN})$ [Fig. $7(\mathrm{a})]$. Here, the jump forces were $\sim 30 \%$ weaker for the +500 and $-500 \mathrm{mV}$ polymers, indicating that the electrical stimulation had a deleterious effect on binding strength of molecular-level interactions. In addition, the jump length progressively increased from $+500 \mathrm{mV}(304.7 \pm 14.5 \mathrm{~nm})$ followed by $-500 \mathrm{mV}(344.5 \pm$ $10.9 \mathrm{~nm})$ and then the nonbiased polymer $(270.0 \pm 12.5 \mathrm{~nm})$ [Fig. 7(b)]. Thus, it is observed that the electrical stimulation lowers the overall interaction stiffness of the jumps, i.e., when the force values are divided by the length $(\mathrm{pN} / \mathrm{nm})$. Plateau forces similarly showed a significant decrease for electrically stimulated polymers $(+500 \mathrm{mV}=63.5 \pm 2.4 \mathrm{pN}$ and $-500 \mathrm{mV}=53.3 \pm 3.2 \mathrm{pN}$ versus nonbiased $=77.5 \pm 2.5 \mathrm{pN}$ ) [Fig. 7(c)], while their lengths showed a different dependence to the jumps [Fig. 7(d)].

Analysis of the number of jumps and plateaus can be used to estimate the number of de-adhesion "contacts" that are formed, particularly those involving $\alpha 5 \beta 1-\mathrm{FN}$ complexes given that these represent a majority of the interactions. Figure 7(e) shows that there is a significant decrease in the number of jumps per SCFS curve for both the $+500 \mathrm{mV}$ (5 jumps) and $-500 \mathrm{mV}$ (6.9 jumps) versus nonbiased (8.8 jumps) polymers. This reduced number of de-adhesion contacts in combination with the decrease in jump forces (and effective interaction stiffness) is suggested to be a contributing factor to the concomitant decrease in single cell de-adhesion forces in electrical stimulation scheme (1).

Interestingly, the number of plateau interactions on the $-500 \mathrm{mV}$ polymer (1.9 plateaus) was comparable to the nonbiased polymer (1.9 plateaus) and significantly greater than the $+500 \mathrm{mV}$ polymer ( 0.8 plateaus) [Fig. 7(f)], supporting the high de-adhesion energy observed for the $-500 \mathrm{mV}$ polymers in Fig. 5(c). As mentioned, plateaus are suggested to be due to bound receptors that lose their connection with the internal cytoskeleton, ${ }^{29}$ causing subsequent extraction of the membrane (with bound receptor) in the form of a tether that contributes to increased adhesion energy. The different propensity of membrane tethers to occur on either the oxidized and reduced polymers is not clear though it interestingly suggests that their interactions can have different affinity depending on the redox surface properties and associated adsorbed protein layer. They may accordingly have interactions that are independent of those interactions associated with jumps, i.e., receptors connected to the cytoskeleton, due to differences in their prevalence [cf. Figs. 7(e) and 7(f)].

\section{Electrical stimulation scheme (2)}

The forces of jumps and plateaus showed a similar trend with a progressive decrease from the nonbiased polymer ( jump $=58.6 \pm 1.5 \mathrm{pN} ; \quad$ plateau $=75.6 \pm 4.5 \mathrm{pN}), \quad$ followed by switching to the oxidized ( jump $=54.5 \pm 1.4 \mathrm{pN}$; plateau $=68.4 \pm 2.8 \mathrm{pN}$ ) and then the reduced polymer ( jump $=49.6 \pm 1.4 \mathrm{pN}$; plateau $=57.5 \pm 2.5 \mathrm{pN}$ ) [Figs. 8 (a) and 8(b)]. Furthermore, the effects of electrical stimulation on the lengths of both jumps and plateaus were very different to electrical stimulation scheme (1). For example, the oxidized polymer showed the highest jump length $(323.1 \pm 15.5 \mathrm{~nm})$ [Fig. 8(c)] while the same polymer surface gave the lowest plateau length $(887.7 \pm 65.7 \mathrm{~nm})$ [Fig. 8(d)]. In terms of the number of de-adhesion "contacts," there was a decrease in the number of jumps per SCFS curve in the order of nonbiased polymers (8.4 jumps), $+500 \mathrm{mV}$ (7.4 jumps), and $-500 \mathrm{mV}$ (6 jumps) [Fig. 8(e)]. These trends in the number of de-adhesion "contacts" and their unbinding forces did not correlate with the single cell de-adhesion forces in electrical stimulation scheme (2), namely, the enhanced adhesion on the $+500 \mathrm{mV}$ polymers. This seemingly highlights the complexity of effects when electrical stimulation is applied either during protein adsorption [electrical stimulation scheme (1)] or after protein adsorption and when switching from the oxidized to reduced states [electrical stimulation scheme (2)]. Due to this lack of direct correlation between the molecularlevel analysis and single cell adhesion in electrical stimulation scheme (2), we suggest that electrical stimulation has effects on promoting enhanced or "cooperative" interactions, which are likened to be greater than the sum of their individual, molecular de-adhesion "contacts" and responsible for stronger single cell adhesion on the oxidized polymer.

In conclusion, the SCFS is expected to progress the ability to quantify early events of molecular recognition and cell adhesion on stimuli-responsive polymers and biomaterials. It will be of interest to corroborate this information to longer-term adhesion and developmental processes such as growth, proliferation, and differentiation. We similarly expect the work to have broader impact in the fields of functional materials, smart polymers, and organic bioelectronics that are currently being used to control cell interactions via switching of their surface properties. ${ }^{54,55}$ The latter is also very topical in emerging reviews on designing material cues for controlling molecular-level interactions involved in transmitting signals across the cell-material interface, including regulating cell function and gene expression. ${ }^{56}$

\section{ACKNOWLEDGMENTS}

The authors are grateful for the support of the Chinese Scholarship Council and continued financial support of the Australian Research Council under the Australian Research Fellowship (DP110104359) of Michael J. Higgins and Laureate Fellowship (FL110100196) of Gordon G. Wallace. Funding from the Australian Research Council Centre of Excellence Scheme (Project No. CE 140100012) is gratefully acknowledged. The authors would like to thank the Australian National Nanofabrication Facility-Materials node for equipment use.

${ }^{1}$ M. D. Mager, V. LaPointe, and M. M. Stevens, Nat. Chem. 3, 582 (2011).

${ }^{2}$ M. M. Stevens and J. H. George, Science 310, 1135 (2005). 
${ }^{3}$ M. A. Cole, N. H. Voelcker, H. Thissen, and H. J. Griesser, Biomaterials 30, 1827 (2009).

${ }^{4}$ P. M. Mendes, Chem. Soc. Rev. 37, 2512 (2008).

${ }^{5}$ H. W. Ooi, S. Hafeez, C. A. van Blitterswijk, L. Moroni, and M. B. Baker, Mater. Horiz. 4, 1020 (2017).

${ }^{6}$ A. L. Hook, N. H. Voelcker, and H. Thissen, Acta Biomater. 5, 2350 (2009).

${ }^{7}$ T. Sun, G. Wang, L. Feng, B. Liu, Y. Ma, L. Jiang, and D. Zhu, Angew. Chem. 116, 361 (2004).

${ }^{8}$ J. Lahann, S. Mitragotri, T.-N. Tran, H. Kaido, J. Sundaram, I. S. Choi, S. Hoffer, G. A. Somorjai, and R. Langer, Science 299, 371 (2003).

${ }^{9}$ E. Wischerhoff, K. Uhlig, A. Lankenau, H. G. Börner, A. Laschewsky, C. Duschl, and J. F. Lutz, Angew. Chem. Int. Ed. 47, 5666 (2008).

${ }^{10}$ C. L. Yeung, P. Iqbal, M. Allan, M. Lashkor, J. A. Preece, and P. M. Mendes, Adv. Funct. Mater. 20, 2657 (2010).

${ }^{11}$ J. Auernheimer, C. Dahmen, U. Hersel, A. Bausch, and H. Kessler, J. Am. Chem. Soc. 127, 16107 (2005).

${ }^{12}$ A. F. Quigley, J. M. Razal, B. C. Thompson, S. E. Moulton, M. Kita, E. L. Kennedy, G. M. Clark, G. G. Wallace, and R. M. Kapsa, Adv. Mater. 21, 4393 (2009).

${ }^{13}$ X. Liu, K. J. Gilmore, S. E. Moulton, and G. G. Wallace, J. Neural Eng. 6, 065002 (2009).

${ }^{14}$ K. J. Gilmore, M. Kita, Y. Han, A. Gelmi, M. J. Higgins, S. E. Moulton, G. M. Clark, R. Kapsa, and G. G. Wallace, Biomaterials 30, 5292 (2009).

${ }^{15}$ B. C. Thompson, S. E. Moulton, J. Ding, R. Richardson, A. Cameron, S. O’Leary, G. G. Wallace, and G. M. Clark, J. Control. Release 116, 285 (2006).

${ }^{16}$ R. Wadhwa, C. F. Lagenaur, and X. T. Cui, J. Control. Release 110, 531 (2006).

${ }^{17}$ D. Svirskis, J. Travas-Sejdic, A. Rodgers, and S. Garg, J. Control. Release 146, 6 (2010).

${ }^{18}$ C. Salto, E. Saindon, M. Bolin, A. Kanciurzewska, M. Fahlman, E. W. H. Jager, P. Tengvall, E. Arenas, and M. Berggren, Langmuir 24, 14133 (2008).

${ }^{19}$ K. M. Persson, R. Karlsson, K. Svennersten, S. Löffler, E. W. H. Jager, A. Richter-Dahlfors, P. Konradsson, and M. Berggren, Adv. Mater. 23, 4403 (2011).

${ }^{20}$ Y. Pei, J. Travas-Sejdic, and D. E. Williams, Langmuir 28, 8072 (2012).

${ }^{21}$ A. Kotwal and C. E. Schmidt, Biomaterials 22, 1055 (2001).

${ }^{22}$ K. Svennersten, M. H. Bolin, E. W. Jager, M. Berggren, and A. Richter-Dahlfors, Biomaterials 30, 6257 (2009).

${ }^{23}$ A. M. Wan, D. J. Brooks, A. Gumus, C. Fischbach, and G. G. Malliaras, Chem. Commun. 35, 5278 (2009).

${ }^{24}$ A. Wan, R. M. Schur, C. K. Ober, C. Fischbach, D. Gourdon, and G. G. Malliaras, Adv. Mater. 24, 2501 (2012).

${ }^{25}$ A. Gelmi, M. J. Higgins, and G. G. Wallace, Small 9, 393 (2013).

${ }^{26}$ P. J. Molino, Z. Yue, B. Zhang, A. Tibbens, X. Liu, R. Kapsa, M. J. Higgins, and G. G. Wallace, Adv. Mater. Interfaces 1, 1300122 (2014).

${ }^{27}$ D. Boettiger, Curr. Opin. Cell Biol. 24, 592 (2012).

${ }^{28}$ J. Helenius, C.-P. Heisenberg, H. E. Gaub, and D. J. Muller, J. Cell Sci. 121, 1785 (2008).
${ }^{29}$ J. Friedrichs, K. R. Legate, R. Schubert, M. Bharadwaj, C. Werner, D. J. Müller, and M. Benoit, Methods 60, 169 (2013).

${ }^{30}$ C. M. Franz, A. Taubenberger, P. H. Puech, and D. J. Muller, Sci. STKE 2007, pl5 (2007).

${ }^{31}$ J. Friedrichs, J. Helenius, and D. J. Muller, Nat. Protoc. 5, 1353 (2010).

${ }^{32}$ A. Taubenberger, D. A. Cisneros, J. Friedrichs, P. H. Puech, D. J. Muller, and C. M. Franz, Mol. Biol. Cell 18, 1634 (2007).

${ }^{33}$ P. H. Puech, K. Poole, D. Knebel, and D. J. Muller, Ultramicroscopy 106, 637 (2006).

${ }^{34}$ A. V. Taubenberger, D. W. Hutmacher, and D. J. Muller, Tissue Eng. Part B Rev. 20, 40 (2013).

${ }^{35}$ S. Sankaran, L. Jaatinen, J. Brinkmann, T. Zambelli, J. Vörös, and P. Jonkheijm, ACS Nano 11, 3867 (2017).

${ }^{36}$ H. Zhang, P. J. Molino, G. G. Wallace, and M. J. Higgins, Sci. Rep. 5, 13334 (2015).

${ }^{37}$ L. Jaatinen, E. Young, J. Hyttinen, J. Vörös, T. Zambelli, and L. Demkó, Biointerphases 11, 011004 (2016).

${ }^{38}$ L. F. Kadem, M. Holz, K. G. Suana, Q. Li, C. Lamprecht, R. Herges, and C. Selhuber-Unkel, Adv. Mater. 28, 1799 (2016).

${ }^{39}$ J. L. Hutter and J. Bechhoefer, Rev. Sci. Instrum. 64, 1868 (1993).

${ }^{40}$ E. Sariisik, C. Popov, J. P. Müller, D. Docheva, H. Clausen-Schaumann, and M. Benoit, Biophys. J. 109, 1330 (2015).

${ }^{41}$ M. J. Higgins and G. G. Wallace, Polym. Rev. 53, 506 (2013).

${ }^{42}$ H. Bachman, J. Nicosia, M. Dysart, and T. H. Barker, Adv. Wound Care 4, 501 (2015).

${ }^{43}$ S. Johansson, G. Svineng, K. Wennerberg, A. Armulik, and L. Lohikangas, Front. Biosci. 2, d126 (1997).

${ }^{44}$ P. Knox, S. Crooks, and C. S. Rimmer, J. Cell Biol. 102, 2318 (1986).

${ }^{45}$ J. Friedrichs, J. Helenius, and D. J. Müller, Proteomics 10, 1455 (2010).

${ }^{46}$ D. W. Schmidtke and S. L. Diamond, J. Cell Biol. 149, 719 (2000).

${ }^{47}$ J. Y. Wong, R. Langer, and D. E. Ingber, Proc. Natl. Acad. Sci. 91, 3201 (1994).

${ }^{48}$ M. Bergkvist, J. Carlsson, and S. Oscarsson, J. Biomed. Mater. Res. Part A 64, 349 (2003).

${ }^{49}$ Y. Chen, Y. Wu, and J. Cai, Biochem. Biophys. Res. Commun. 361, 391 (2007).

${ }^{50}$ J. R. Hull, G. S. Tamura, and D. G. Castner, Biophys. J. 93, 2852 (2007).

${ }^{51}$ P. J. Molino, M. J. Higgins, P. C. Innis, R. Kapsa, and G. G. Wallace, Langmuir 28, 8433 (2012).

${ }^{52}$ E. C. Williams, P. A. Janmey, J. D. Ferry, and D. F. Mosher, J. Biol. Chem. 257, 14973 (1982).

${ }^{53}$ F. Li, S. D. Redick, H. P. Erickson, and V. T. Moy, Biophys. J. 84, 1252 (2003).

${ }^{54}$ J. Rivnay, R. M. Owens, and G. G. Malliaras, Chem. Mater. 26, 679 (2013).

${ }^{55}$ K. Svennersten, K. C. Larsson, M. Berggren, and A. Richter-Dahlfors, Biochim. Biophys. Acta 1810, 276 (2011).

${ }^{56}$ S. W. Crowder, V. Leonardo, T. Whittaker, P. Papathanasiou, and M. M. Stevens, Cell Stem Cell 18, 39 (2016).

${ }^{57}$ See supplementary material at https://doi.org/10.1116/1.5022713 for histograms of cell modulus as a function of the applied voltage. 